\title{
Inspiring stories: the impact that being part of ERS activities can have on a professional career
}

\author{
Alexander G. Mathioudakis ${ }^{1,2,11}$, Christian Osadnik $\mathbb{1}^{3,11}$, Agnes W. Boots ${ }^{4,11}$, Matteo Bradicich ${ }^{5,6,11}$, \\ Sabine Bartel ${ }^{7,11}$, Rainer Gloeckl ${ }^{8,9,11}$ and Joana Cruz (10)
}

${ }^{1}$ Division of Infection, Immunity and Respiratory Medicine, School of Biological Sciences, The University of Manchester, Manchester, UK. ${ }^{2}$ North West Lung Centre, Wythenshawe Hospital, Manchester University NHS Foundation Trust, Manchester Academic Health Science Centre, Manchester, UK. ${ }^{3}$ Dept of Physiotherapy, Monash University, Melbourne, Australia. ${ }^{4}$ Dept of Pharmacology and Toxicology, Maastricht University, Maastricht, The Netherlands. ${ }^{5}$ Dept of Pulmonology, University Hospital Zurich, Zurich, Switzerland. ${ }^{6}$ Dept of Internal Medicine, Spital Zollikerberg, Zollikerberg, Switzerland. ${ }^{7}$ Dept of Pathology and Medical Biology, University of Groningen, Groningen Research Center for Asthma and COPD (GRIAC), University Medical Center Groningen, Groningen, The Netherlands. ${ }^{8}$ Institute for Pulmonary Rehabilitation Research, Schoen Klinik Berchtesgadener Land, Schoenau am Koenigssee, Germany. ${ }^{9}$ Dept of Pulmonary Rehabilitation, Philipps University of Marburg, German Center for Lung Research (DZL), Marburg, Germany. ${ }^{10}$ Center for Innovative Care and Health Technology (ciTechCare), School of Health Sciences (ESSLei), Polytechnic of Leiria, Leiria, Portugal. ${ }^{11}$ These authors contributed equally.

Corresponding author: Joana Cruz (joana.cruz@ipleiria.pt)

Shareable abstract (@ERSpublications)

In this article, we provide an overview of the impact that being part of the @EuroRespSoc activities can have on a professional career, through the voices of Early Career Members (@EarlyCareerERS) https://bit.ly/32sHNW2

Cite this article as: Mathioudakis AG, Osadnik C, Boots AW, et al. Inspiring stories: the impact that being part of ERS activities can have on a professional career. Breathe 2022; 18: 210217 [DOI: 10.1183/ 20734735.0217-2021].

Copyright @ERS 2022

Breathe articles are open access and distributed under the terms of the Creative Commons Attribution Non-Commercial Licence 4.0.

Received: 22 Oct 2021 Accepted: 18 Jan 2022

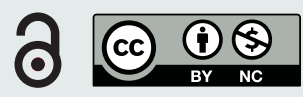

Each year, the European Respiratory Society (ERS) offers many opportunities to support Early Career Members (ECMs) working in the respiratory field in advancing their careers, including fellowships, representation at ERS assemblies, and presentations at the ERS Congress. Through these opportunities, ECMs can meet other respiratory professionals, find synergies, work together and discover new ways to increase their visibility and advance their careers, as well as create new and lasting friendships. In this issue, we provide an overview of the impact that being part of the ERS activities can have on professional careers, through the voices of ECMs. We hope to inspire all ECMs to participate in future ERS opportunities!

\section{Reflections of ECMs on the long-term impact of fellowships on their professional career} ERS guidelines methodology fellowship (Alexander G. Mathioudakis, UK)

ERS is committed to the development of clinical practice guidelines of the highest quality, to facilitate clinicians to practice evidence-based medicine in the diagnosis, assessment, and management of respiratory diseases. ERS guidelines are developed by task forces that are coordinated by the Guidelines Working Group and supported by the two in-house ERS guideline methodologists. The ERS Guidelines Working Group has a strong ethos for supporting the participation of ECMs in the development of guidelines and other official documents, aiming to develop expertise in evidence-based medicine and guidelines methods across the respiratory community.

The contribution of experienced ECMs in guidelines panels is crucial, as their development involves a very demanding and resource-intense process. Each recommendation included in a clinical practice guideline is based on a rigorous systematic review of the literature, usually followed by a meta-analysis, as well as a critical appraisal of all relevant studies and of the body of all available relevant evidence [1, 2]. Finally, an international panel of experts, along with patient representatives, is responsible for developing a recommendation based on all the available evidence around the risks and benefits associated with an intervention, patients' values and preferences, and consideration of the costs [3]. 
The ERS fellowship in guidelines methodology consists of two 3-month placements at Cochrane Iberoamerica (Barcelona, Spain) and at the National Institute for Health and Care Excellence (NICE, Manchester, UK), followed by the participation of the fellow in the development of an ERS clinical practice guideline [4]. Cochrane is a global organisation conducting systematic reviews and meta-analyses of the highest quality and developing the respective methodology, while NICE is a world-leading organisation in developing clinical practice guidelines. During the first placement, fellows are trained in the methods for conducting systematic reviews, meta-analyses, and developing clinical practice guidelines, while in the second placement, they have the opportunity to follow the process of developing and maintaining national clinical practice guidelines, with a strong focus on cost-effectiveness, and gain a better insight into the process and the expertise that is required. Finally, fellows have a great opportunity to consolidate their knowledge and apply it practically, while being involved in the development of an ERS guideline, and working with world-leading experts in a respiratory disease area. The fellowship training programme is very flexible and can adapt to the previous knowledge, experience and current needs and interests of the fellows, but those with previous experience in conducting systematic reviews and meta-analyses and an understanding of the methodology involved in the development of clinical practice guidelines (Grading of Recommendations Assessment, Development and Evaluation (GRADE) methodology [3]) will make the most of these placements.

The ERS guidelines methodology fellowship facilitated a huge leap in my career. The expertise in evidence-based medicine that I consolidated during and after the fellowship led to exciting opportunities. I was able to publish clinically relevant systematic reviews [5-8], and I joined the Cochrane Airways Editorial Board. I also worked with the GRADE working group and have contributed to the expansion of the methodology used for creating guidelines [9-11]. Most importantly, I had the privilege to work more closely with the ERS Guidelines Working Group and, besides my contribution to the ERS Guidelines on the management of sarcoidosis [12], I was also able to co-lead two other important task forces. One of these task forces developed a core outcome set for the management of COPD exacerbation [13-16], and the second assessed factors impacting adherence to international asthma guidelines [17]. Finally, systematic reviews and clinical trials are strongly interlinked, and, during my $\mathrm{PhD}$, I was able to develop further skills in clinical trials methods. Overall, the ERS guidelines methodology fellowship shaped my academic career, and I am very grateful to the ERS for this amazing opportunity!

The guidelines fellowship is currently on hold, but ERS is now developing a Guidelines Methodology Network (www.ersnet.org/science-and-research/ers-clinical-practice-guidelines-methodology-network), that will allow more ECMs to be trained in guidelines methodology and will facilitate their participation in the development of ERS guidelines. It would be my very strong recommendation for people interested in evidence-based medicine to take advantage of these great opportunities.

\section{ERS long-term fellowship (Christian Osadnik, Australia)}

I undertook an ERS long-term research fellowship, in 2014-2015, to conduct novel research in the area of pulmonary rehabilitation in the laboratory of Prof. Thierry Troosters in Leuven, Belgium. Undertaking this fellowship involved quite a big move from my home in Melbourne, Australia! I did so with my young family (my wife and kids, then aged 2 and 4 years) after careful consideration of the many potential pros and cons. Despite the uncertainty associated with such a change, the decision to "go for it" was one that I do not regret.

Despite initial nerves, the support I received from the ERS fellowships team as well as my mentor helped make me feel very welcome. Prof. Troosters leads an inspiring department of clinicians, PhD students and postdoctoral fellows across a diverse range of projects within respiratory disease and rehabilitation medicine. The interconnected university-hospital environment between KU Leuven and UZ Leuven (Gasthuisberg) was simply amazing. This is something we dream of in Australia and rarely get to experience in person (and on such a large scale). I was so appreciative to have been so readily accepted as part of the team (despite my apparently funny Australian accent) and especially grateful to have been provided opportunities for involvement in projects other than my own - something I eagerly accepted.

My specific project was a comprehensive randomised controlled trial examining the effects of "downhill walking" (using a treadmill on an inverted decline angle, see figure 1) in people with COPD. This was completed in conjunction with co-lead author, Dr. Carlos Camillo, and a team of amazing clinicians and researchers. It provided opportunities for learning about muscle physiology, personalised rehabilitation and comprehensive research design. Many lessons learned during this time continue to influence the conduct of my own research even now. 


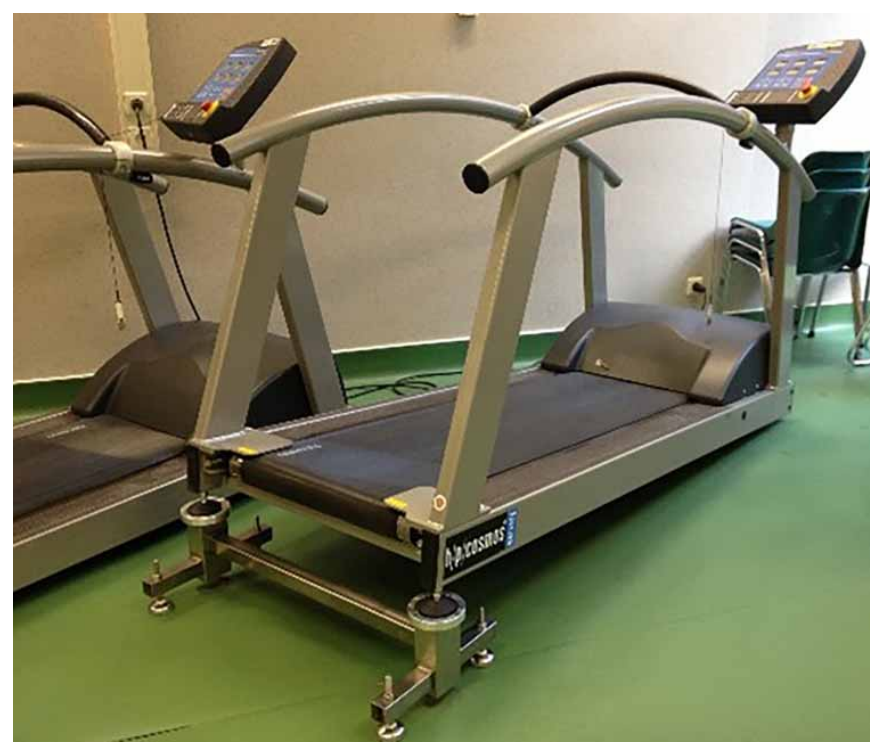

FIGURE 1 Downhill treadmill walking equipment.

In terms of outcomes, I feel the hard work of my fellowship rewarded me with many positive experiences. I developed many new, enduring international professional connections and friendships. I obtained closer engagement with the ERS Groups and Assemblies, and the European Lung Foundation than previously possible. I gained exposure to world-leading international practice and research perspectives. I developed leadership and mentorship skills to supervise clinical research students. I also developed new clinical skills in areas such as cardiopulmonary exercise testing (figure 2), physical activity measurement and analysis, electromagnetic muscle stimulation, and muscle biopsy collection and analysis.

I was fortunate that our completed research was successfully published in the European Respiratory Journal [18] and stimulated much discussion within the field of pulmonary rehabilitation. I subsequently leveraged upon these fellowship outcomes to successfully acquire further postdoctoral funding applications upon my return to Australia. I would simply not have been competitive without international fellowship experience on my CV. A significant personal achievement to have arisen from my ERS fellowship experience was the confidence to establish my own research laboratory focussing on the mentorship of clinician-researchers interested in respiratory medicine and rehabilitation (ResPTlab, www.resptlab.com).

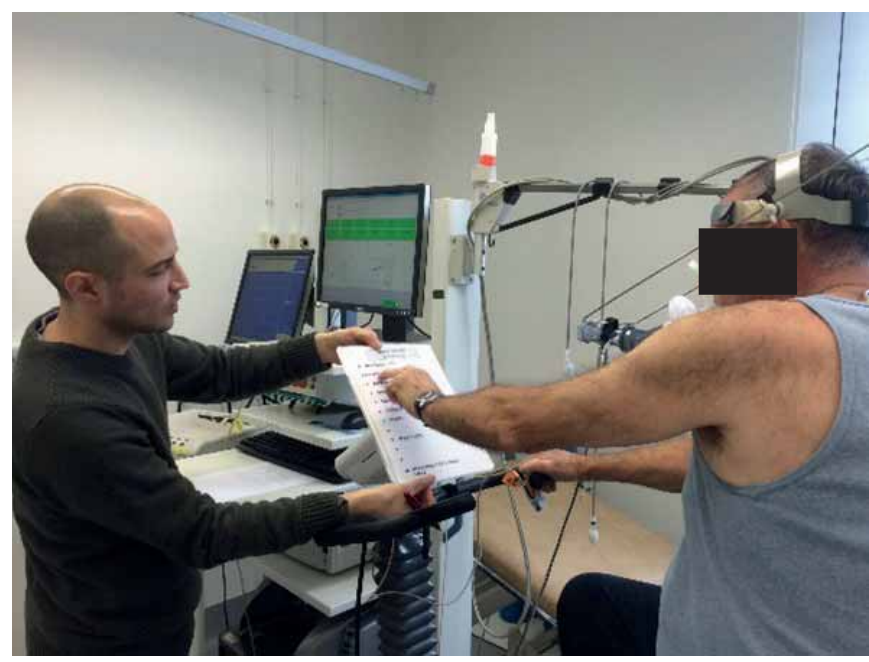

FIGURE 2 Cardiopulmonary exercise testing in the lung function laboratory at UZ Gasthuisberg (Leuven, Belgium). 
I was also recently successful in obtaining a promotion to Associate Professor in the Department of Physiotherapy at Monash University, of which I am immensely proud.

I often look back on my ERS fellowship with great satisfaction at the life experiences that it brought myself and my family. If I were to offer any advice to individuals considering an ERS fellowship, I would wholeheartedly encourage them to have the courage to start a conversation with the person they would like to work with and see what options might be possible. For me, this took place at an ERS International Congress. From there, and after considering your personal situation, do as I did and just "go for it”!

\section{RESPIRE1 Marie Skłodowska-Curie fellowship (Agnes W. Boots, the Netherlands)}

While finishing my PhD thesis in Maastricht, the Netherlands, my supervisors told me it would be worthwhile to think ahead about what I would like to do next and, if "my next" would include science, they recommended I start applying for postdoctoral fellowships. As I could not imagine I would do anything else but science, I followed their advice and applied for various grants including an ERS RESPIRE fellowship. When the news arrived that the fellowship was granted, I felt enormously lucky and a bit terrified at the same time. After all, this fellowship not only meant my first independent postdoctoral project would soon kick off, but it also implied I would live and work in two foreign countries. Only 2 weeks after my official PhD defence, I left my home and family in the Netherlands for Burlington (USA) to start the first part of my RESPIRE fellowship.

At the start, it felt like being thrown into deep water without a life jacket as I was overwhelmed by all the new impressions at my host lab and country, and had no clue where to get started with what. However, after a few weeks, the panic mode slowly switched into a more relaxed one as I found a great place to live and met some wonderful local people via my roommate. At the lab, I started to find my way as well and was able to perform my first experiments without searching for materials or asking for help. Although the first results were not as I anticipated, my host and home supervisors helped me to interpret the data and to feel confident in deciding myself how to proceed. As a toxicologist by training, focused on unravelling redox-related pathways underlying pulmonary diseases, I had always been the outlier in our Pharmacology and Toxicology Department in the Netherlands. Although I never experienced it as such, my stay in the Burlington lab made me realise how great it is to be surrounded by colleagues working on related topics with whom you can discuss content as well as procedures. I truly enjoyed every day at the lab and gained a lot of experience in new techniques and interpreting data from different angles. Outside the lab, I spent most time skiing and hiking in the mountains followed by dinner and drinks downtown with an (inter) national group of friends of continuously changing composition due to everyone's work obligations. Although I found it a bit scary in the beginning to meet new people every time we would hang out and to never be completely at ease with friends who know you well, I was surprised how quickly I adapted to this situation and how genuinely open and interested everyone was. If I had to name one valuable lesson I learnt outside the lab during my time in the USA, it is to always be open and genuinely interested in (new) people as they can enrich your life at any stage for a long period, or even only a day, or a few hours!

Leaving Burlington felt hard. but with the lessons learnt during that stay, the start of my second foreign postdoctoral project in Düsseldorf (Germany) was relatively easy. Adjusting to yet another unknown lab with different routines and methods was no longer making me insecure but rather excited and enthusiastic. I was eager to learn new things while practising what I had already learnt in the USA, although I soon realised that my new knowledge was only the tip of the iceberg and that there was so much more to learn and experience. Setting up a large animal experiment that included the help of the entire lab for instance or isolating and culturing primary cells from tissue samples. One thing I did not struggle with any longer was engaging with new people, finding my spot within the new research group, and enjoying yet another new social life in and outside the lab.

My RESPIRE fellowship at two different foreign labs with international teams taught me how to become an independent researcher who is not afraid to ask for input or help if needed. On both a professional and personal level, my fellowship allowed me to grow by increasing my self-knowledge and confidence as well as my critical view on both my own work and that of peers. The stimulating and transparent approach of my home and host supervisors has definitely contributed to that growth! Therefore, I think it is fair to say that my fellowship has shaped me not only as scientist but also as teacher and mentor for my (PhD) students. And it brought me collaborators and friends for life!

The experience of being part of the Early Career Member Committee (ECMC)

Roles and short-term effects of being a (current) ECMC member (Matteo Bradicich, Switzerland)

The ECMC is a first, meaningful step towards an active role in the ERS. The ECMC is a committee of ECMs (ERS members under 40), each of whom represent the young colleagues of their own ERS Assembly. 
I decided to apply for this position in Autumn 2020, as it would have become vacant in December of the same year. The application process was relatively easy, as it was a step-by-step online procedure on the myERS website, and consisted of a brief presentation of my career and a proposal for activities and goals that I would like to implement in the following 3 years in charge.

I decided to apply since the ERS has been, since the very beginning of my medical and research activities, a proactive group of mentors, which fostered my research interests and taught me rigorous scientific methods in order to remain critical and up to date in my work and to keep my mind open to new ideas, enhancing international teamwork. I think that ERS has greatly contributed to the medical professional that I am today. The possibility of proactively bringing my experience in the ERS community, to advocate for a high-level, international research and to foster the translation of this knowledge into clinical practice made me apply for a position as ECM representative for ERS Assembly 4, as sleep medicine is my main research interest.

The first 10 months as ECM representative have been intense and active. I usually work on two levels: with the ECMC and in my own Assembly. Within the ECMC, we discuss and run many projects on a general ERS level, for example the online survey on "COVID-19 and the impact on training". The most intense moments are the ones before and during the ERS International Congress, as we discuss what we will be implementing this year and what we could propose for the upcoming year considering the feedback from the current Congress. Another stimulating role in the ECMC is being responsible for the international relations with other international societies' ECM associations. The main goal is to foster international collaboration even between different medical fields, which are often intertwined - for instance allergology and clinical immunology. Even during the COVID-19 pandemic, we are planning to sponsor each other's activities via our social media channels. In the future, we would like to invite to the ERS Congresses international guests from other societies. In my Assembly, I am responsible for being the linking element between young and senior experts. My main activities consist of communicating and sponsoring new events, managing calls, and promoting and structuring educational events. For these activities, the ECM representatives have a role of utmost importance. On one side, they have the opportunity of getting in touch with the ERS community and proactively supporting ERS activities; on the other, they help the central ERS organisations (first of all the Assemblies) to understand what they are at most interested in. Examples of my activities in ERS Assembly 4 are the creation and management of our official Twitter and Instagram accounts, in which I am supported by other engaged ECMs; discussing ideas for the upcoming webinars; writing article digests; and planning other educational events with the senior figures.

Another interesting part of being an ECMC representative is in planning future ERS projects: the interpretation of the future educational and research needs of our community is a difficult yet very stimulating challenge, where the teamwork with the other ECM representatives and senior ERS officers plays a crucial role. This position offered me the chance to step into an active and stimulating world and I would like to keep on with my commitment in the ERS by applying for further ERS officer positions at the end of my mandate as ECM representative.

A role in the ECMC is a stimulating experience and a personal and professional growth opportunity through constant, gradual engagement where you are called to take responsibility in numerous ERS activities, while being supported by a network of colleagues and senior mentors. I would definitely recommend taking this first step into a broader professional future as an active team player in the ERS.

Roles and long-term effects of being a past ECMC member (Sabine Bartel, the Netherlands)

At the time that I started in the ECMC (September 2016) as ECM representative for Assembly 3 (Basic and Translational Science), almost half of the committee consisted of new members, and the chair was also new, meaning that it took a while until everything was running smoothly and everybody knew what to do. I decided to take over the tasks of planning the ECM session at the annual ERS Congress, and since I love the Lung Science Conference and was going there regularly anyway, I also helped set up the ECM programme for this conference. I really enjoyed being a part of the ECMC and not only have I learned a lot from this position, but I am also convinced that it has helped me a lot in the past and will help my future career in respiratory science.

The first advantage is that being involved in the ECMC teaches you how the ERS really works, for example how different proposals are evaluated and what they need to be successful. Furthermore, you'll get to know which steps/processes/people are behind the scenes. This will help you in the future to be more successful with proposals for sessions or research seminars or other types of funding, like 
fellowships. Additionally, you will get to know the right people to ask for advice should you need it, which in my opinion is the most valuable advantage of being a member of the ECMC.

Within the ECMC, you will be working together as a team with other young professionals from all the Assemblies and different backgrounds. It was a fantastic experience to meet all those colleagues and I still have a very good connection to most of them. Over the 3 years of our mandate, we built up a strong professional network, resulting in some joint projects and publications but also a lot of fun at our meetings. Next to the network at the ECMC peer level, I was also involved in the leadership of Assembly 3. Our Assembly Head and Secretary at that time were very inclusive and involved me in decisions and important discussions. This meant that I played an active role in setting up the Congress programme at the Zurich meeting, in writing and supporting proposals for sessions or research seminars, as well as general proceedings of the Assembly. In the final year of my mandate, I represented the ECMC in the Science Council, which is the highest scientific board in the ERS. It was incredibly fascinating to see how decisions are made in this board and how the different Assembly heads interact with each other. The committee members were also very open to me as ECMC member and I was able to make some very valuable connections by getting to know many leading experts in the lung field.

A third point that I would like to mention is the positive impact on your CV. Taking over an elected and proactive role in a committee of the largest respiratory society certainly has some added value. It shows that you are known in your field (as the positions were elected), that you have established a good network (as you worked with many of the leading experts in the field on different committees) and that you are proactive and willing to go the extra mile (in a voluntary position). All these points will be very valuable to both academic but also non-academic career paths and it will definitely help you to stand out of the crowd when you apply for your next job or grant.

\section{Long-term impact of presenting at the ERS Congress on a scientific career (Rainer Gloeckl,} Germany)

I am a clinical exercise physiologist, and I attended my first ERS Congress in 2008. Back then, I submitted an abstract which was accepted for a thematic poster session. I was very excited to present the first preliminary data from my thesis at my first international conference. I was so nervous I even had sleep difficulties 2 weeks in advance of that presentation. Presenting my study results in English (which is not my mother language) further increased the tension. However, after completing my poster presentation I was very happy and proud and did not regret that I had submitted that abstract.

Over the following years, I kept on submitting abstracts to the ERS Congress and got the opportunity to present research findings in different formats like thematic poster presentations, poster discussions, and oral sessions. I gained many insights into different presentation styles. Furthermore, I received feedback from colleagues that had a different point of view and provided me with suggestions on how to optimise presentation of results or to add any further analyses. This valuable feedback often improved the quality of the papers that resulted from these abstracts. Furthermore, I also received many new ideas and inspirations for future research. It is also a very satisfying feeling when other researchers are interested in the research you are doing and visit your poster, for example, to ask questions and discuss the findings with you.

I always enjoyed the communication and networking opportunities during the ERS Congresses. Beyond the scientific exchange, there are also plenty of opportunities to have a private chat with colleagues. Over the years, I developed many good personal contacts and even close friendships. So, meeting each other at the annual ERS Congress feels a bit like a class reunion which makes you feel an active part of the "ERS family”. Networking during the ERS Congresses can be a very crucial part. Being an active participant during the Congresses by presenting your own research and getting involved in discussions can open up several further opportunities. The representatives of your specific Assembly get to know you and might invite you for further tasks like reviewing the Assembly abstracts for the next Congress. By reviewing and rating the abstracts you can contribute to optimising the quality of the scientific sessions. As a positive side-effect, this task can also improve your reviewer skills.

Presenting frequently at the ERS can also result in invitations to become a (co-)chair of sessions. Although it requires quite some work to prepare a session as a chair, it provides you with new valuable experiences by being "on the other side". By doing so, you have the opportunity to lead scientific discussions that may stimulate the audience and create new ideas and inspirations for future research.

Finally, I would like to share a quick story. Some years ago, I was invited to speak at a large ERS symposium what was very honourable and exciting. After my talk, a foreign research group from 


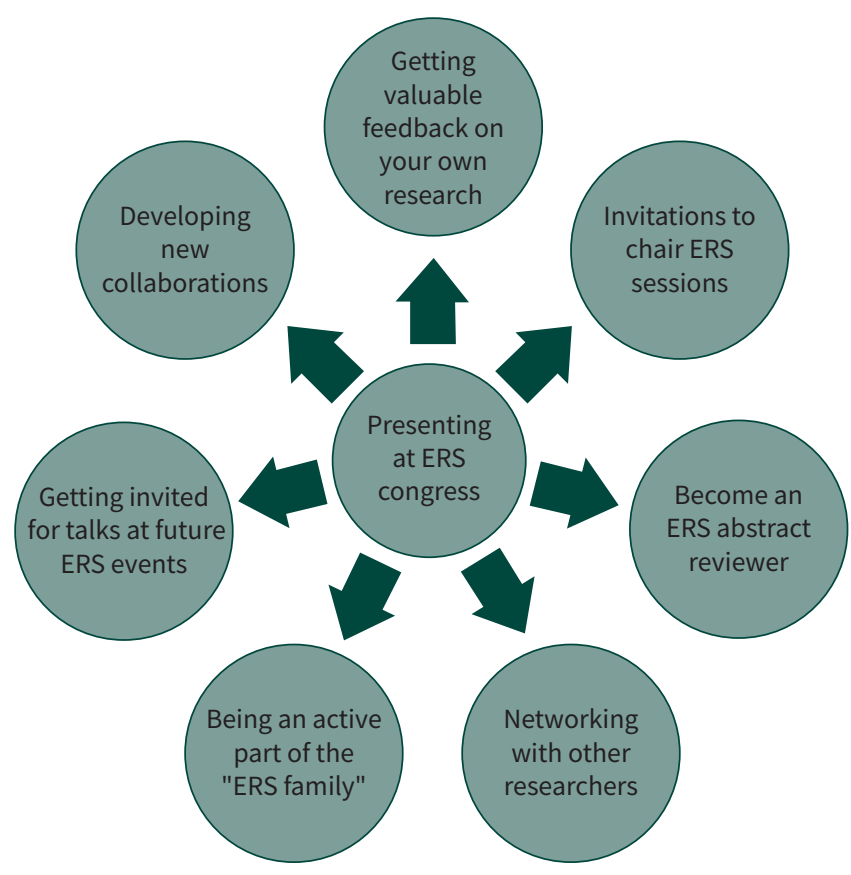

FIGURE 3 Potential impact and opportunities of presenting at the ERS Congress.

Switzerland came to me and asked me if I would like to collaborate with them on the topic of my talk (on which they were currently planning a multicentre trial). I agreed, and in 2021, this collaboration resulted in a joined publication in Thorax [19].

Presenting at the ERS Congress can bring many opportunities and potential impacts to our professional career (figure 3). The message is clear: getting out of your "shell" and exposing yourself can be scary sometimes, but it can provide you with great experiences and opportunities.

\section{Concluding remarks}

We have provided inspiring testimonials from ECMs who overcame their fears and took a step forward in search of new experiences to enhance their professional career. We hope that more ECMs will follow their example and (continue to) contribute actively to the ERS activities. Take the active option!

Conflict of interest: A.G. Mathioudakis has nothing to disclose. C. Osadnik reports receiving grants or contracts from Royal Australian College of General Practitioners, Royal Australian College of General Practitioners and Pat Cosh Trust Fund. Payment or honoraria for lectures, presentations, speakers' bureaus, manuscript writing or educational events received from Novartis, Australia. Disclosures made outside the submitted work. A.W. Boots has nothing to disclose. M. Bradicich reports receiving payment or honoraria for lectures, presentations, speakers' bureaus, manuscript writing or educational events from ERS International Congress 2021. Support for attending meetings and/or travel from ERS International Congress 2021. Disclosures made outside the submitted work. S. Bartel reports receiving consulting fees from Bencard Allergie $\mathrm{GmbH}$, outside the submitted work. R. Gloeckl has nothing to disclose. J. Cruz has nothing to disclose.

Support statment: A.G. Mathioudakis was supported by the National Institute for Health Research Manchester Biomedical Research Centre (NIHR Manchester BRC). J. Cruz acknowledges the support of the Center for Innovative Care and Health Technology (ciTechCare) of the Polytechnic of Leiria, which is funded by Portuguese national funds provided by Fundação para a Ciência e Tecnologia (FCT) (UIDB/05704/2020 and UIDP/05704/2020).

\section{References}

$1 \quad$ Miravitlles M, Tonia T, Rigau D, et al. New era for European Respiratory Society clinical practice guidelines: joining efficiency and high methodological standards. Eur Respir J 2018; 51: 1800221.

2 Fally M, Nagavci B, Tonia T, et al. Real-life evidence in ERS clinical practice guidelines: from foes to friends. Eur Respir J 2021; 58: 2101718. 
3 Guyatt G, Oxman AD, Akl EA, et al. GRADE guidelines: 1. Introduction-GRADE evidence profiles and summary of findings tables. J Clin Epidemiol 2011; 64: 383-394.

4 Morty RE, Donnelly LE, Stolz D, et al. The ERS fellowship portfolio: fostering excellence and diversity. Eur Respir J 2019; 54: 1901503.

5 Normansell R, Kew KM, Mathioudakis AG. Interventions to improve inhaler technique for people with asthma. Cochrane Database Syst Rev 2017; 3: CD012286.

6 Janjua S, Mathioudakis AG, Fortescue R, et al. Prophylactic antibiotics for adults with chronic obstructive pulmonary disease: a network meta-analysis. Cochrane Database Syst Rev 2021; 1: CD013198.

7 Mathioudakis AG, Chatzimavridou-Grigoriadou V, Corlateanu A, et al. Procalcitonin to guide antibiotic administration in COPD exacerbations: a meta-analysis. Eur Respir Rev 2017; 26: 160073.

8 Mathioudakis AG, Salakari M, Pylkkanen L, et al. Systematic review on women's values and preferences concerning breast cancer screening and diagnostic services. Psychooncology 2019; 28: 939-947.

9 Guyatt GH, Ebrahim S, Alonso-Coello P, et al. GRADE guidelines 17: assessing the risk of bias associated with missing participant outcome data in a body of evidence. J Clin Epidemiol 2017; 87: 14-22.

10 Brozek JL, Canelo-Aybar C, Akl EA, et al. GRADE Guidelines 30: the GRADE approach to assessing the certainty of modeled evidence-An overview in the context of health decision-making. $J$ Clin Epidemiol 2021; 129: 138-150.

11 Akl EA, Morgan RL, Rooney AA, et al. Developing trustworthy recommendations as part of an urgent response (1-2 weeks): a GRADE concept paper. J Clin Epidemiol 2021; 129: 1-11.

12 Baughman RP, Valeyre D, Korsten P, et al. ERS clinical practice guidelines on treatment of sarcoidosis. Eur Respir J 2021; 58: 2004079.

13 Mathioudakis AG, Abroug F, Agusti A, et al. Core outcome set for the management of acute exacerbations of chronic obstructive pulmonary disease: the COS-AECOPD ERS Task Force study protocol. ERJ Open Res 2020; 6: 00193-2020.

14 Mathioudakis AG, Abroug F, Agusti A, et al. ERS Statement: A core outcome set for clinical trials evaluating the management of chronic obstructive pulmonary disease (COPD) exacerbations. Eur Respir J 2021; in press [https://doi.org/10.1183/13993003.02006-2021].

15 Mathioudakis AG, Moberg M, Janner J, et al. Outcomes reported on the management of COPD exacerbations: a systematic survey of randomised controlled trials. ERJ Open Res 2019; 5: 00072-2019.

16 Mathioudakis AG, Janner J, Moberg M, et al. A systematic evaluation of the diagnostic criteria for COPD and exacerbations used in randomised controlled trials on the management of COPD exacerbations. ERJ Open Res 2019; 5: 00136-2019.

17 Mathioudakis AG, Tsilochristou O, Adcock IM, et al. ERS/EAACI statement on adherence to international adult asthma guidelines. Eur Respir Rev 2021; 30: 210132.

18 Camillo CA, Osadnik CR, Burtin C, et al. Effects of downhill walking in pulmonary rehabilitation for patients with COPD: a randomised controlled trial. Eur Respir J 2020; 56: 2000639.

19 Guler SA, Hur SA, Stickland MK, et al. Survival after inpatient or outpatient pulmonary rehabilitation in patients with fibrotic interstitial lung disease: a multicentre retrospective cohort study. Thorax 2021; in press [http://dx.doi.org/10.1136/thoraxjnl-2021-217361]. 